\title{
Salvatore Maria Perrella, Mjriam di Nazaret, la donna che con- duce a Dio. In dialogo fra cristiani e islamici, Cinisello Balsamo, San Paolo, 2021, 216 pp., $18 €$. ISBN 978-88-9222-457-5.
}

Ante la creciente presencia del islam en Occidente y el recrudecimiento del fundamentalismo y del terrorismo en las últimas décadas, el diálogo interreligioso parece más urgente que nunca, como de hecho se desprende de la propuesta de "fraternidad y amistad social" que el papa Francisco ha hecho en su última encíclica Fratelli tutti. En esta línea, el prolífico teólogo Salvatore Maria Perrella — sacerdote de los Siervos de María, profesor de la Pontificia Facultad Marianum de Roma y miembro del consejo directivo de la Pontificia Academia Mariana Internacional - ha publicado un ensayo sobre la Virgen María como referente cultural y antropológico para el encuentro entre cristianos y musulmanes, cual Mater unitatis, "patrimonio común" de enorme" potencial pacificador". Baste recordar, como el autor hace en la introducción, que ambas religiones reconocen en María un modelo excelente de fe, religiosidad, servicio, honestidad y, especialmente, de oración.

La ilustración de la portada de la obra, el mosaico de la Virgen con el niño de la tribuna de la Basílica de Santa Sofía de Estambul, recientemente reconvertida en mezquita, pone en aviso sobre la actualidad del tema, algo usual en el autor, atento a los signos de los tiempos y a las cuestiones mariológicas de vanguardia, como, por ejemplo, el ecumenismo o las apariciones y mariofanías. En esta ocasión, Perrella parte de la actitud dialogante que la Iglesia, desde la declaración conciliar Nostra aetate, ha mantenido con las religiones, especialmente con el mundo islámico. Sin caer en la ingenuidad de no reconocer las dificultades que ello implica, el mariólogo napolitano apuesta por descubrir en María un lugar teológico y vivencial de encuentro entre las dos religiones abrahámicas, afrontando, a partir de la lectio magistralis que Benedicto XVI hizo en 2006 en la Universidad de Ratisbona, una cuestión epistemológica de fondo: esclarecer la relación entre fe y razón, religión y violencia. El enfoque constructivo del autor responde a las iniciativas de acercamiento que después de la polémica suscitada por dicho discurso se produjeron: el documento sobre la Fraternidad humana para la paz mundial y la convivencia común firmado en 2019 por el papa Francisco y el gran imán de Al-Ahzar, Ahmad 
Al-Tayyb, y la Comisión Mariana Internacional Cristiana Musulmana creada en el seno de la PAMI en 2020; sin olvidar la vocación al diálogo interreligioso que los Siervos de María han demostrado desde 1983 en sus capítulos generales, subrayando la reciprocidad fraterna que entre musulmanes y cristianos puede producirse, si se repara en los puntos en que ambos convergen, siendo clave para ello el aprecio que en el islam se tiene a Maryam, la madre del profeta Jesús.

Se ha de valorar la rica bibliografía con la que Perrella fundamenta sus argumentaciones, ofreciendo un aparato crítico interdisciplinar muy rico, no solo desde la perspectiva cristiana, sino también musulmana, además de ayudarse de ciencias humanas como la filosofía y la antropología. Entre otros aspectos metodológicos destaca el contraste que hace entre la doctrina musulmana y la cristiana, de manera que, conforme va exponiendo la primera, remite al Catecismo de la Iglesia Católica en las notas a pie de página. En este sentido, el autor es fiel al modo de conducir el diálogo en su propia obra, desde el respeto y el conocimiento mutuos.

Constituida por seis capítulos, la obra comienza abordando la situación del cristianismo en la postmodernidad, época caracterizada por un fuerte secularismo que, a su vez, se expresa en el relativismo, el racionalismo que niega lo metafísico y religioso, el subjetivismo individualista y egoísta, la cultura de la muerte, el ateísmo "vulgar" que no piensa y, en definitiva, la expulsión de Dios. Frente a esto, Perrella reivindica que la religión no es un fenómeno irracional o una fuente de problemas, sino una realidad esencial de la sociedad que puede contribuir al bien común, a la cultura del encuentro y de la paz, propósito para el que el diálogo interreligioso es fundamental.

En el segundo capítulo defiende el discurso de Benedicto XVI en Ratisbona, sosteniendo que este pretendía realmente deslegitimar la motivación religiosa de la violencia, venga de donde venga, además de advertir que si hubo un tiempo en el que los creyentes menoscabaron la razón, los hombres del presente, por el contrario, no han de caer en el desinterés por la religión. Superada la polémica, el papa emérito reconocía los efectos positivos del discurso al haber despertado en los estudiosos del islam el interés por clarificar una cuestión clave, la de la relación de esta religión con la violencia y la razón.

En el tercer capítulo se detiene en las dificultades que durante siglos se han producido entre cristianos y musulmanes. Estas se remontan a la jihad y a las cruzadas, considerándose al islam, con el 
inicio de la secularización europea en el siglo xVIII, una religión fanática e intolerante, mientras que, para el mundo islámico, Occidente, identificado con el cristianismo, representa una cultura opresora e invasora. Por otro lado, tanto el cristianismo como el islam sufren una fuerte crisis, uno a causa del secularismo y el otro, del fundamentalismo. A estas diferencias se han de sumar las doctrinales. Aunque el islam comparta la adoración por el único Dios, existen importantes divergencias, sobre todo por lo que respecta a la divinidad de Jesús, en cuanto que el fuerte monoteísmo que lo caracteriza rechaza el concepto trinitario de Dios confesado por el cristianismo.

Después de esto, el autor pasa a analizar el islam, cuyo epicentro de fe concierne al Dios de Abrahán que se habría revelado al último de sus profetas, Mahoma (Muhammad). Los musulmanes se consideran una comunidad de fe (Umma), cuya cabeza es Dios (Allah) y cuyo ideal sociopolítico es la comunidad de Medina fundada por Mahoma. Seguidamente, el autor hace una buena síntesis del credo islámico, tratando la profesión de fe (la shahâda) relativa al monoteísmo y a Mahoma, los ángeles, los demonios, los espíritus que influyen en los hombres (ginn), los profetas, el Corán (transcripción literal de la Palabra de Dios), las tradiciones sobre Mahoma y su mensaje (la Sunna), las Escrituras (reflejo de la custodiada en el cielo y que fue revelada en la Torah, los Salmos y el Evangelio, si bien estos — según el islam-fueron falsificados por los profetas y discípulos, hallándose plena y definitivamente en el Corán), la predestinación y la escatología. Por lo que respecta a los pilares del culto islámico, Perrella señala cinco: la jaculatoria (shahâda), la oración ritual (cinco veces al día), el ayuno (sobre todo el Ramadam), la limosna legal y la peregrinación a La Meca. Finalmente, analiza algunas de las costumbres, instituciones y lugares islámicos, como, por ejemplo: la mezquita, cementerios, alimentos, vestimentas, velo, calendario, fiestas y la llamada a la misión o proselitismo $\left(d a^{\prime} w a\right)$.

En el cuarto capítulo expone las diferencias que existen entre el islam y el cristianismo, no antes sin recordar, como ya señalara el Concilio Vaticano II, algunos aspectos positivos como que el islam adora al Dios único, tiene a Jesús por profeta, honra a su Madre, cree en el juicio final y estima altamente la vida moral, la oración, el ayuno y la limosna. Las diferencias, bien expresadas por los epígrafes de los apartados que las explican, son: a) al "Dios Trinidad y Amor", el islam contrapone el "Dios uno y único"; b) al hombre "hijo de Dios", el 
islam concibe el hombre como"siervo de Dios"; c) a la redención de Cristo, la responsabilidad moral de cada uno; d) a la ley interior del Espíritu, una moral coránica preceptiva; e) a la teología universalista de las religiones, el exclusivismo musulmán; f) al estado democrático y plural, el estado confesional islámico, teocrático, sin que los cristianos tengan los mismos derechos. A pesar de las divergencias, el autor sigue abogando por un diálogo basado en el encuentro respetuoso entre personas, la colaboración mutua a favor de la justicia y la paz, el conocimiento de ambas religiones - competencia de los especialistas-y el intercambio de experiencias de la propia vida religiosa. Aunque el diálogo sea realmente difícil, apostilla el autor, es necesario el esfuerzo por parte de todos"en nombre del Dios Misericordia y Amor"y de María, "patrimonio compartido" que fomenta "experiencias de encuentro capaces de deslegitimar y debilitar el desencuentro y el fundamentalismo".

Se ha de reconocer el honesto arrojo del autor cuando, a la hora de señalar las diferencias, antes de pasar al capítulo sobre la imagen que el islam tiene de María, apela a la interpretación del Corán desde la exégesis histórico-crítica y las ciencias literarias, para advertir que la divergencia doctrinal fundamental radica en que el islam niega la divinidad de Jesús y, por tanto, que María sea Madre de Dios, debiéndose esto a que Mahoma "redimensionó" a ambos desde su concepción religiosa férreamente monoteísta, habiéndolos conocido no por la Biblia, sino por tradiciones orales basadas en los evangelios apócrifos.

En el quinto capítulo expone la doctrina mariana musulmana, comenzando por el Corán, donde María ocupa un lugar destacado, si se tiene en cuenta que es la única mujer llamada por su nombre, nada más y nada menos que 34 veces, apareciendo en 13 suras y con cinco episodios sobre su vida: su nacimiento, el retiro en el templo, la anunciación, el parto y la defensa de la calumnia contra su maternidad, esta última por influencia de la polémica judía que sostenía que esta fuera irregular. De estos episodios se deducen cuatro prerrogativas de María: su predestinación, la purificación (que nada tiene que ver con la inmunidad del pecado original), la maternidad virginal (antes del parto) y la eminente dignidad de ser la madre del profeta Jesús, excelencia por la que incluso es venerada e invocada. En un segundo apartado observa cómo María es propuesta por el islam como modelo para los creyentes del Dios de Abrahán. Sometida a Dios, 
Maryam es considerada una verdadera musulmana, habida cuenta de que la característica esencial del islam es el sometimiento total a Allah. María es así modelo a imitar por su fe, religiosidad (sobre todo por la oración y el ayuno), pureza y honestidad, tenida incluso por los místicos musulmanes como un ideal de unión con Dios. Por todo ello, concluye el autor, se explica la devoción que María despierta en los musulmanes, especialmente los del cercano Oriente, empatía esta por la que dedica un tercer apartado a las múltiples expresiones de religiosidad popular mariana que se dan en el islam.

En el sexto y último capítulo, propone a María como modelo de inspiración para una cultura de la paz entre las religiones, "mujer interreligiosa" capaz de encender en los creyentes del Dios de Abrahán - judíos, cristianos y musulmanes - sentimientos de fraternidad contrarios al fundamentalismo. María, insiste el autor, representa el "paradigma de la respuesta plenaria del creyente a Dios" y el"patrimonio común" de las tres grandes religiones que "constantemente recuerda que el verdadero nombre de Dios es Šālŏm" (Paz).

En suma, la obra del profesor Perrella constituye un ejemplo excelente de cómo desde la teología se puede trabajar en favor de una fraternidad universal que implique no solo a los cristianos, sino también a los creyentes de otras religiones como el islam, demostrando que el misterio de María representa un lugar teológico de encuentro, reflexión, entendimiento y hermandad.

\author{
Álvaro Román Villalón \\ Facultad de Teología San Isidoro de Sevilla \\ Sevilla. España \\ alvaroroman@sanisidoro.net \\ https://orcid.org/0000-0003-0119-9990
}

